\title{
Does Labor Augmentation with Oxytocin Increase the Risk of Postpartum Hemorrhage? A Randomized Controlled Trial
}

\section{Amr Mansy*}

Obstetrics \& Gynecology, Faculty of Medicine, Alexandria University, Egypt

*Corresponding author: Amr Mansy, Obstetrics \& Gynecology, Faculty of Medicine, Alexandria University, Egypt, Tel: +201227494992; Fax: +201227494992; E-mail: dr_amrmansy@yahoo.com

Received date: June 04, 2017; Accepted date: August 22, 2017; Published date: September 02, 2017

Copyright: $\odot 2017$ Mansy A. This is an open-access article distributed under the terms of the Creative Commons Attribution License, which permits unrestricted use, distribution, and reproduction in any medium, provided the original author and source are credited.

\begin{abstract}
Labour augmentation aims to shorten labour so prevent complications related to prolonged labour. There is evidence that a significant proportion of women with uncomplicated pregnancies are subjected to routine augmentation of labour with oxytocin in spite of the general rule that labour augmentation should only be performed for valid indications. Obstetric hemorrhage is one of the leading causes of maternal mortality in developing countries, accounting for $10 \%-30 \%$ of direct maternal deaths. The aim of the study was to compare between labour augmentation with oxytocin and no augmentation on the total volume of blood loss during vaginal delivery. The study included 250 cases admitted to the emergency department in El-Shatby maternity university hospital, group A (Oxytocin group) 125 cases received augmentation by oxytocin infusion using $2.5 \mathrm{IU}$ oxytocin in $500 \mathrm{cc}$ saline with a slow rate of 20-30 drops/minute, group B (Control group) 125 cases received only 500 cc saline. The amount of blood loss during the $3^{\text {rd }}$ stage of labor and the $1^{\text {st }}$ hour after delivery of the placenta $\left(4^{\text {th }}\right.$ stage $)$ have been estimated.
\end{abstract}

Results showed that the total volume of blood loss in group A ranged from 100 to 700 ml with the mean of 230.9 $\pm 99.3 \mathrm{ml}$, on the other hand it ranged from 100 to $650 \mathrm{ml}$ with mean of $181.5 \pm 83.1 \mathrm{ml}$ in group $\mathrm{B}$. the calculated $\mathrm{p}$ value was 0.001 , so there was a significant statistical difference between both groups regarding the total volume of blood loss, so we concluded that use of oxytocin in labor augmentation increase the volume of blood loss.

Keywords: Oxytocin; Postpartum haemorrhage; Labor augmentation

\section{Introduction}

Difficult labour or dystocia is defined as slow progress of labour caused by inefficient uterine contractions, abnormal fetal presentation or position, inadequate bony pelvis or abnormal maternal pelvic soft tissues. It is associated with maternal and perinatal morbidity and mortality [1]. The incidence of difficult labour is not accurately known as there is no universal consensus about the definition of delayed first stage of labour [2]. The term "Failure to progress" has become an increasing description of delayed labour and one of the leading causes of caesarean section [3]. Augmentation of labour is the process of uterine stimulation using intravenous oxytocin infusion to increase frequency, duration and intensity of contractions after the onset of spontaneous labour. It is used to treat delayed labour when uterine contractions are not strong or coordinated enough to cause cervical dilatation [4]. Labour augmentation aims to shorten labour so prevent complications related to prolonged labour. There is evidence that a significant proportion of women with uncomplicated pregnancies are subjected to routine augmentation of labour with oxytocin in spite of the general rule that labour augmentation should only be performed for valid indications [5].

There have also been reports of unstructured use of labour augmentation, where women are given oxytocin inadequately or unnecessarily. Augmentation with synthetic oxytocin may result in uterine hyperstimulation, adverse effects as fetal hypoxia and uterine rupture [6]. For low-income countries to remain on track towards the fifth Millennium Development Goal, evidence-based guideline was required for their health workers to comprehensively improve intrapartum care through appropriate patient selection and use of effective interventions. In this regard, the World Health Organization (WHO) published recommendations for induction of labour to consolidate the guidance for effective interventions related to intrapartum care [7]. Obstetric hemorrhage is one of the leading causes of maternal mortality in developing countries, accounting for $10 \%-30 \%$ of direct maternal deaths [8]. Clinical studies of the effect of oxytocin administration during labour on the risk of PPH have reported conflicting results [9]. In this study authors tried to find an effect of labour augmentation using oxytocin infusion on the risk of development of postpartum hemorrhage.

\section{Study Objectives}

\section{Primary objective}

To compare between labour augmentation with oxytocin and no augmentation on the total volume of blood loss during vaginal delivery.

\section{Secondary objective}

To study the effect of labour augmentation by oxytocin on the development of postpartum hemorrhage (PPH), conversion to cesarean section (CS), fetal and maternal adverse effects. 


\section{Methods}

- Trial Design: Double blinded randomized controlled trial.

- Method or randomization: Closed envelope.

- Alexandria University Ethics Committee approval was obtained.

- Participants: The study included 250 cases admitted to the emergency department in El-Shatby maternity university hospital fulfilled the study eligibility criteria.

\section{Eligibility criteria}

1. Any multiparous woman with one or more successful non complicated vaginal delivery.

2. All women admitted in the latent phase of $1^{\text {st }}$ stage of labour.

3. Cephalic presentation, with engaged head.

4. Intact membrane.

5. Frequent uterine contractions with cervical dilatation $\leq 3 \mathrm{~cm}$ with cervical effacement $\geq 50 \%$.

6. Age 20 to 35 years.

7. Gestational age: Full term.

8. Expected fetal weight 2500 to $3500 \mathrm{~kg}$

9. $\mathrm{Hb} \geq 10 \mathrm{gm} / \mathrm{dl}$ on admission.

10. No contraindications of vaginal delivery.

11. No contraindications of oxytocin or tocolytic use (as terbutaline if needed) as hypertension, hyperthyroidism and cardiac diseases.

\section{Interventions}

After signing a well-informed written consent to declare their participation in the study, all cases were divided randomly using a closed envelope method into two groups:

Group A (Oxytocin group): 125 cases received augmentation by oxytocin infusion using $2.5 \mathrm{IU}$ oxytocin in $500 \mathrm{cc}$ saline with a slow rate of 20-30 drops/min.

Group B (Control group): 125 cases received only $500 \mathrm{cc}$ saline.

After randomization and enrollment in the study, all cases of both groups have been checked for the following parameters:

Progress of labour:

- Duration of the remaining time of the $1^{\text {st }}$ stage.

- Fetal heart rate monitoring every one hour for $20 \mathrm{~min}$ to exclude abnormal heart rate pattern as late or variable decelerations, brady or tachycardia and abnormal beat to beat variability.

- Vaginal examination every 30-45 min to check cervical effacement \& dilatation, condition of membranes whether spontaneously ruptured or need artificial rupture of membranes. NB- all cases of both groups that membranes not spontaneously ruptured during the $1^{\text {st }}$ stage were offered artificial rupture of membrane using a sterile amniohook or Kocher forceps under sterile direct vision.

Any case that developed sings of fetal distress of both groups, was subjected to hold augmentation (if belonged to oxytocin group), advised to lie on her left lateral position and received glucose 5\% infusion,

- If the condition improved within 10 mins, resuming enrollment in the study.

- If the condition recurred augmentation stopped,
- If the condition persisted cesarean section was offered as fetal blood sampling and fetal blood $\mathrm{pH}$ were not available at our hospital.

Any case developed signs of uterine hyperstimulation in both groups was subjected to hold augmentation (if belonged to oxytocin group), advised to lie on her left lateral position and received Intravenous terbutaline as Ventolin $0.5 \mathrm{mg} / \mathrm{ml}$, using a $1 \mathrm{~mL}$ syringe, $0.5 \mathrm{~mL}(250 \mu \mathrm{g})$ of terbutaline was drawn up then added to a $10 \mathrm{~mL}$ syringe and made up to $10 \mathrm{~mL}$ with sodium chloride $0.9 \%(25 \mu \mathrm{g} / \mathrm{mL})$, given slowly intravenous in $50 \mu \mathrm{g}$ boluses up to $250 \mu \mathrm{g}$, maternal pulse monitoring was ensured whilst bolus doses administered.

Once the cervix was fully dilated all women were transferred to the delivery room with her infusion and continuous fetal monitoring was done, no anaesthesia was administered except local anesthesia if episiotomy was needed, after delivery of the anterior shoulder all cases of both groups were subjected to the active management of 3rd stage approved by our hospital:

- Bladder emptying.

- 10 IU oxytocin infusion.

- Controlled cord traction.

- Uterine massage.

After clamping of the cord a clean disposable plastic sheet that was previously folded on delivery table, would be unfolded under the woman buttocks and its lower end being directed to a calibrated jug to estimate the amount of blood loss.

The amount of blood loss during the $3^{\text {rd }}$ stage of labor and the $1^{\text {st }}$ hour after delivery of the placenta ( $4^{\text {th }}$ stage) would be estimated.

During the $4^{\text {th }}$ stage any signs of uterine atony were observed and recorded, also any need for other oxytocics as oxytocin, misoprostol or Carbetocin was recorded. Any case required further interventions for PPH management as surgical intervention also been recorded.

Indications of cesarean section in both groups:

- Failure of progress of labour (as failure of head decent in spite of full cervical dilatation) with fetal or maternal distress.

- Uterine hyperstimulation not responding to tocolytic with persistent fetal distress.

- Persistent Fetal distress with expected fetal hypoxia.

- Other indications as severe intrapartum hemorrhage.

\section{Outcomes}

Primary outcomes: Total volume of blood loss during the $3^{\text {rd }}$ and $4^{\text {th }}$ stage of labour using a disposable plastic sheet with blood collecting reservoir and calibrated jug.

\section{Secondary outcomes:}

- Time of first stage from admission to full cervical dilatation using stopwatch.

- Occurrence of uterine hyperstimulation, it is defined as single contraction lasting $2 \mathrm{~min}$ or more, or five or more contractions in a $10 \mathrm{~min}$ period. It can cause impairment to uteroplacental blood flow and result in fetal heart rate abnormalities, fetal hypoxia and fetal damage.

- Occurrence of fetal distress; signs of fetal distress are abnormal beat to beat variability, fetal bradycardia and late decelerations.

- Occurrence of uterine atony and need for extra uterotonics. 
Citation: Mansy A (2017) Does Labor Augmentation with Oxytocin Increase the Risk of Postpartum Hemorrhage? A Randomized Controlled

Page 3 of 6

- Conversion to cesarean section and its indication.

\section{Sample size calculation}

Based on confidence level of $95 \%$, confidence interval of 5 , and population proportion of $10 \%$ based on data obtained from the hospital registration department.

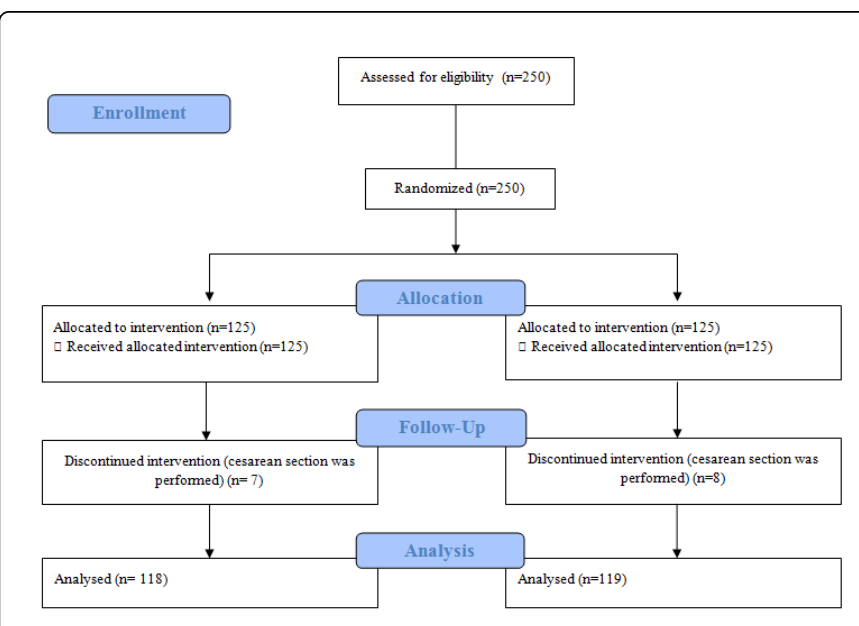

Figure 1: Study Flow Diagram.

\section{Randomization \& blinding}

Randomization depended on a closed envelops randomly selected by the study principal investigator and when opened it showed whether this participant belonged to oxytocin or placebo group, the investigator prepared a syringe filled with oxytocin or saline to be given to the resident physician responsible for the delivering case and asked her/him to inject it into the saline bottle assumed to be given intravenously to the study cases. Blinding was a double one as both the resident physician who was responsible for follow and delivery of the case and the delivering woman did not know if the drug used was oxytocin or placebo (saline), and only the principal investigator (The Study Author) who knew the composition of the syringe content.

\section{Statistical methods}

All collected data have been statistically analyzed using a computer based software SPSS version 19.

\section{Results}

Time \& venue: The study started on $1^{\text {st }}$ January 2017 and ended by $18^{\text {th }}$ April 2017 after completion of the whole required cases, the study was conducted in Alexandria University Maternity Hospital "El-Shatby Hospital" in Egypt (Figure 1).

\section{Baseline demographic data}

Age \& parity: On comparing both groups regarding age and parity, it was found that there was no statistical significance regarding age and parity in both groups as the calculated $p$ values were $0.204 \& 0.18$ for age \& parity respectively, as shown in Table 1.

\section{Outcomes}

\section{1) Primary outcome}

Volume of blood loss: The total volume of blood loss in group A ranged from 100 to $700 \mathrm{ml}$ with the mean of $230.9 \pm 99.3 \mathrm{ml}$, on the other hand it ranged from 100 to $650 \mathrm{ml}$ with mean of $181.5 \pm 83.1 \mathrm{ml}$ in group B. the calculated $p$ value was 0.001 , so there was a significant statistical difference between both groups regarding the total volume of blood loss, as shown in Table 2.

\begin{tabular}{|l|l|l|l|l|}
\hline \multicolumn{2}{|c|}{} & $\begin{array}{l}\text { Group A } \\
\text { (N=125) }\end{array}$ & $\begin{array}{l}\text { Group B } \\
\text { (N=125) }\end{array}$ & P value \\
\hline \multirow{2}{*}{ Age } & Range & $20-35$ & $20-35$ & \multirow{2}{*}{0.204} \\
\cline { 2 - 5 } & Mean \pm SD & $27.4 \pm 3.8$ & $26.8 \pm 3.7$ & \\
\hline \multirow{3}{*}{ Parity } & Range & 42795 & 42795 & \multirow{2}{*}{0.18} \\
\cline { 2 - 5 } & Median & 2 & 2 & \\
\hline
\end{tabular}

Table 1: Comparing both groups regarding Age \& Parity.

\begin{tabular}{|l|l|l|l|}
\hline Volume of blood loss & $\begin{array}{l}\text { Group A } \\
\text { (N=118) }\end{array}$ & $\begin{array}{l}\text { Group B } \\
\text { (N=119) }\end{array}$ & P value \\
\hline Range & $100-700$ & $100-650$ & \multirow{2}{*}{0.001} \\
\hline Mean \pm SD & $230.9 \pm 99.3$ & $181.5 \pm 83.1$ & \\
\hline
\end{tabular}

Table 2: Comparing both groups regarding volume of blood loss.

\section{2) Secondary outcomes}

Time of the first stage: The time of first stage in group A ranged from one hour and $6 \mathrm{~min}$ to $6 \mathrm{~h}$ and $58 \mathrm{~min}$ with a mean of $3 \mathrm{~h}$ and 22 $\min \pm 1 \mathrm{~h}$ and $32 \mathrm{~min}$, in group B it ranged from one hour and $2 \mathrm{~min}$ to $6 \mathrm{~h}$ and $45 \mathrm{~min}$ with a mean of $3 \mathrm{~h}$ and $18 \mathrm{~min} \pm 1 \mathrm{~h}$ and $26 \mathrm{~min}$, there is no significant effect on labor augmentation on shortening of first stage as the calculated $\mathrm{p}$ value was 0.888 , as shown in Table 3 .

\begin{tabular}{|l|l|l|l|}
\hline Time of $\mathbf{1}^{\text {st }}$ stage & $\begin{array}{l}\text { Group } \\
\text { (N=125) }\end{array}$ & $\begin{array}{l}\text { Group } \\
\text { (N=125) }\end{array}$ & P value \\
\cline { 1 - 2 } Range (Hours: Minutes) & $01: 06-06: 58$ & $01: 02-06: 45$ & \multirow{2}{*}{0.888} \\
\cline { 1 - 2 } \pm Mean SD & $03: 22 \pm 01: 32$ & $03: 18 \pm 01: 26$ & \\
\hline
\end{tabular}

Table 3: Comparing both groups regarding the time of first stage.

Uterine hyperstimulation: Uterine hyperstimulation was recorded in 3 cases in group A and in one case in group B, there was no significant difference regarding uterine hyperstimulation as the calculated $p$ value was 0.314 , as shown in Table 4 .

- OR: $0.33,95 \%$ CI 0.03 to 3.25

- Relative Risk Reduction (RRR) $=-2 \%$

- Absolute relative risk (ARR) $=-1.6 \%$

- Number Need to Treat $(\mathrm{NTT})=-625$

Fetal distress: There was no statistical difference in fetal distress regarding both studied groups as shown in Table 5; in group A, 6 cases have bradycardia compared to 2 cases in group B, 2 cases in group A have late decelerations compared to one case in group $\mathrm{B}$. 
Citation: Mansy A (2017) Does Labor Augmentation with Oxytocin Increase the Risk of Postpartum Hemorrhage? A Randomized Controlled

Page 4 of 6

- OR: $0.44,95 \%$ CI 0.13 to 1.48

- Relative Risk Reduction (RRR) $=-1.25 \%$

- Absolute relative risk (ARR): $-4 \%$

Number Need to Treat (NTT): -250

\begin{tabular}{|l|l|l|l|}
\hline Uterine Hyperstimulation & $\begin{array}{l}\text { Group A } \\
\text { (N=125) }\end{array}$ & $\begin{array}{l}\text { Group B } \\
\mathbf{( N = 1 2 5 )}\end{array}$ & P value \\
\hline Yes & $3(2.4 \%)$ & $1(0.8 \%)$ & \multirow{2}{*}{0.314} \\
\hline No & $122(97.6 \%)$ & $124(99.2 \%)$ & \\
\hline
\end{tabular}

Table 4: Comparing both groups regarding uterine hyperstimulation.

\begin{tabular}{|l|l|l|l|}
\hline Fetal distress & $\begin{array}{l}\text { Group A } \\
\text { (N=125) }\end{array}$ & $\begin{array}{l}\text { Group B } \\
(\mathbf{N}=125)\end{array}$ & P value \\
\hline Bradycardia & $6(66.7 \%)$ & $2(50 \%)$ & 0.151 \\
\hline Late decelerations & $2(22.2 \%)$ & $1(25 \%)$ & 0.562 \\
\hline Absent BBV & $1(11.1 \%)$ & $1(25 \%)$ & 1 \\
\hline Total & $9(7.2 \%)$ & $4(3.2 \%)$ & \\
\hline
\end{tabular}

Table 5: Comparing both groups regarding fetal distress.

Uterine atony after vaginal delivery: As shown in Table 6, 3 cases in group A versus one case in group $\mathrm{B}$, that showed uterine atony, the calculated $\mathrm{p}$ value was 0.34

- $\quad$ OR: $0.33,95 \%$ CI 0.034 to 3.22

- Relative Risk Reduction (RRR) $=-2.25 \%$

- Absolute relative risk (ARR): $-1.8 \%$

- Number Need to Treat (NTT): -560

\begin{tabular}{|l|l|l|l|}
\hline Uterine Atony after VD & Group A (N=118) & Group B (N=119) & P value \\
\hline Yes & $3(2.6 \%)$ & $1(0.8 \%)$ & \multirow{2}{*}{0.34} \\
\hline No & $115(97.4 \%)$ & $118(99.2 \%)$ & \\
\hline
\end{tabular}

Table 6: Comparing both groups regarding uterine atony after vaginal delivery.

Extra uterotonics: In group A: 14 cases needed extra uterotonics versus 9 cases in group B as shown in Table 7, there was no significant difference between both groups.

- OR: $0.64,95 \%$ CI 0.27 to 1.53

- Relative Risk Reduction (RRR) $=-0.57 \%$

- Absolute relative risk (ARR): $-4.3 \%$

- Number Need to Treat (NTT): -230

\section{Conversion to cesarean section and its indications}

In group A: 7 cases converted to CS, versus 6 cases in group B with no statistical difference regarding both groups.

The indications of CS conversion were mainly due to failed vaginal delivery, fetal distress and uterine inertia.

In group A: 7 cases were converted to CS; 4 cases due to failed progress of labour in spite of good and regular uterine contractions, 1 case due to evident fetal distress and 2 cases due to secondary uterine inertia, on the other hand in group B: 6 cases have been converted to CS, 5 of them due to failed progress of labor and one due to fetal distress.

\begin{tabular}{|l|l|l|l|}
\hline Extra Uterotonics & $\begin{array}{l}\text { Group A } \\
\text { (N=118) }\end{array}$ & $\begin{array}{l}\text { Group B } \\
\mathbf{( N = 1 1 9 )}\end{array}$ & P value \\
\hline Yes & $14(11.9 \%)$ & $9(7.6 \%)$ & \multirow{2}{*}{0.264} \\
\hline No & $104(88.1 \%)$ & $110(92.4 \%)$ & \\
\hline
\end{tabular}

Table 7: Comparing both groups regarding use of extra uterotonics.

The calculated $\mathrm{p}$ values regarding conversion to CS and indications of CS were non significant as shown in Tables 8 and 9.

- OR: $0.86,95 \%$ CI 0.28 to 2.62

- Relative Risk Reduction (RRR) $=-0.17 \%$

- Absolute relative risk (ARR): $-0.8 \%$

- Number Need to Treat (NTT): -125

\begin{tabular}{|l|l|l|l|}
\hline CS & $\begin{array}{l}\text { Group A } \\
\text { (N=125) }\end{array}$ & $\begin{array}{l}\text { Group B } \\
(\mathbf{N}=125)\end{array}$ & P value \\
\hline Yes & $7(5.6 \%)$ & $6(4.8 \%)$ & 0.776 \\
\hline No & $118(94.4 \%)$ & $119(95.2 \%)$ & \\
\hline
\end{tabular}

Table 8: Comparing both groups regarding conversion to cesarean section.

\begin{tabular}{|l|l|l|l|}
\hline $\begin{array}{l}\text { Indications of } \\
\text { CS }\end{array}$ & $\begin{array}{l}\text { Group A } \\
\text { (N=7) }\end{array}$ & $\begin{array}{l}\text { Group B } \\
(\mathbf{N}=6)\end{array}$ & \multirow{2}{*}{ P value } \\
\cline { 1 - 2 } Failed VD & $4(57.1 \%)$ & $5(83.3 \%)$ & \multirow{2}{*}{0.759} \\
\hline Fetal distress & $1(14.3 \%)$ & $1(16.7 \%)$ & \\
\hline Uterine inertia & $2(28.6 \%)$ & $0(0 \%)$ & $0(0 \%)$ \\
\cline { 1 - 3 } Others & $0(0 \%)$ & & \\
\cline { 1 - 3 } & & & \\
\end{tabular}

Table 9: Comparing both groups regarding indication of conversion to cesarean section.

\section{Other analyzed data}

Condition of membranes: In group A, 82 cases underwent spontaneous rupture of membranes and 43 cases underwent artificial rupture, in group B, 87 cases and 38 cases underwent spontaneous and artificial rupture of membranes respectively; there was no statistical significance as the calculated $\mathrm{p}$ value was 0.5 as shown in Table 10.

- OR: $1.06,95 \%$ CI 0.72 to 1.57

- Relative Risk Reduction (RRR) $=0.06 \%$

- Absolute relative risk (ARR): $4.4 \%$

- $\quad$ Number Need to Treat (NTT): 22.7

Episiotomy: There was no significant difference regarding cases underwent episiotomy in both groups as 58 cases in group A underwent episiotomy and 66 cases in group B, calculated $p$ value was 0.332, as shown in Table 11. 
- OR: $1.13,95 \%$ CI 0.73 to 1.74

- Relative Risk Reduction (RRR) $=0.11 \%$

- Absolute relative risk (ARR): $1.6 \%$

- $\quad$ Number Need to Treat (NTT): 62.5

\begin{tabular}{|l|l|l|l|}
\hline $\begin{array}{l}\text { Rupture } \\
\text { membranes }\end{array}$ & $\begin{array}{l}\text { Group A } \\
\text { (N=125) }\end{array}$ & $\begin{array}{l}\text { Group B } \\
\mathbf{( N = 1 2 5 )}\end{array}$ & P value \\
\hline Spontaneous & $82(65.5 \%)$ & $87(69.9 \%)$ & 0.77 \\
\hline Artificial & $43(34.4 \%)$ & $38(30.4 \%)$ & \\
\hline
\end{tabular}

Table 10: Comparing both groups regarding mode of rupture of membranes.

\begin{tabular}{|l|l|l|l|}
\hline Episiotomy & $\begin{array}{l}\text { Group A } \\
\text { (N=118) }\end{array}$ & $\begin{array}{l}\text { Group B } \\
\mathbf{( N = 1 1 9 )}\end{array}$ & P value \\
\cline { 1 - 3 } Yes & $58(49.2 \%)$ & $66(55.5 \%)$ & 0.332 \\
\hline No & $60(50.8 \%)$ & $53(44.5 \%)$ & \\
\hline
\end{tabular}

Table 11: Comparing both groups regarding episiotomy.

\section{Discussion}

As the criteria for diagnosis of prolonged labour are not strictly applied by some clinicians and a large number of practitioner prefer the use of oxytocin for augmentation of labour to decrease the time of first stage and decrease the incidence of post-partum haemorrhage, the current study compared the use of oxytocin augmentation versus no augmentation on women attended the emergency department of obstetrics and gynaecology in Alexandria University hospital who fulfilled the inclusion criteria of the study, results showed that there was no significant advantages of the use oxytocin on decrease the time of first stage, decrease incidence of episiotomy, decrease incidence of fetal distress, decrease incidence of conversion to caesarean section, on the other hand we found that oxytocin use significantly increase the amount of blood loss during the third and fourth stage of labour and so it may increase the risk of PPH. Regarding the risk of development of PPH in labour augmentation; Belghiti et al., conducted a population based, cohort nested case control study on 106 French hospitals from December 2004 through November 2006 and they found that Oxytocin during labour appeared to be an independent risk factor for severe $\mathrm{PPH}[10]$.

Same findings was found by Khireddine et al., that in low risk women, induction of labor, regardless of the method used, is associated with a higher risk of PPH than spontaneous labor [11]. In 2013 a metaanalysis published on Cochrane library reviewed the effect of labor augmentation by oxytocin on the duration of first stage, fetal and maternal adverse effects and on the risk of conversion to cesarean section, they found that no significant effect on reduction of maternal and fetal adverse effects, conversion to cesarean section, but the was a significant effect on shortening of first stage [12]. Other previous clinical studies have reported an association between augmentation of labour and PPH. One case control study of 108 women found that women with $\mathrm{PPH}$ were exposed to higher amounts of oxytocin during labour [13].

In a population based study including 153000 women, Sheiner et al. reported a significant association between labour augmentation with oxytocin and PPH [9]. Two other studies found similar ORs, with a risk of hemorrhage 1.6 times higher in women receiving oxytocin during labour $[14,15]$. Results from a multicentre hospital-based study in Latin America, including 11,323 women delivered vaginally, 211 of whom had severe PPH, conclude that oxytocin during labour is not associated with severe PPH. Moreover, its incidence of severe PPH was higher, albeit not statistically significant, in women who received oxytocin during labour (2.4\%) than in women who did not $(1.9 \%)$; similarly, a higher, but not significant, risk of blood transfusion was associated with oxytocin use during labour (adjusted OR: 2.0, 95\% CI 0.7 to 5.4$)$ [16].

\section{Conclusion}

Abuse of oxytocin to labour augmentation has significant effect on increasing the risk of postpartum hemorrhage and volume of blood loss in the third and fourth stage of labor. Oxytocin augmentation has no effect in reduction of the duration of first stage of labour, risk of fetal and maternal complications and no effect on increase or decrease the risk of conversion to cesarean section. Criteria of labour augmentation should be strictly applied to cases of prolonged or difficult first stage associated with weak, non-coordinate uterine contractions.

Registration: Alexandria Faculty of Medicine Research Authority, Alexandria, Egypt.

\section{Funding: None.}

Competing interests: None.

Ethical approval: By Alexandria Faculty of Medicine Ethical committee.

\section{References}

1. Ronel D, Wiznitzer A, Sergienko R, Zlotnik A, Sheiner E (2012) Trends, risk factors and pregnancy outcome in women with uterine rupture. Arch Gynecol Obstet 285: 317-321.

2. Kjaergaard H, Olsen J, Ottesen B, Dykes AK (2009) Incidence and outcomes of dystocia in the active phase of labor in term nulliparous women with spontaneous labor onset. Acta Obstet Gynecol Scand 88: 402-407.

3. Boyle A, Reddy UM, Landy HJ, Huang CC, Driggers RW, et al. (2013) Primary cesarean delivery in the United States. Obstet Gynecol 122: 33-40.

4. Brown HC, Paranjothy S, Dowswell T, Thomas J (2013) Package of care for active management in labour for reducing caesarean section rates in low-risk women. Cochrane Database Syst Rev 9: 004907.

5. Bernitz S, Oian P, Rolland R, Sandvik L, Blix E (2014) Oxytocin and dystocia as risk factors for adverse birth outcomes: a cohort of low-risk nulliparous women. Midwifery 30: 364-370.

6. Selin L, Almstrom E, Wallin G, Berg M (2009) Use and abuse of oxytocin for augmentation of labor. Acta Obstet Gynecol Scand 88: 1352-1357.

7. WHO recommendations for induction of labour (2011) Geneva: World Health Organization.

8. Khan KS, Wojdyla D, Say L, Gülmezoglu AM, Van Look PF (2006) WHO analysis of causes of maternal death: a systematic review. Lancet 367: 1066-1074.

9. Sheiner E, Sarid L, Levy A, Seidman DS, Hallak M (2005) Obstetric risk factors and outcome of pregnancies complicated with early postpartum hemorrhage: a population-based study. J Matern Fetal Neonatal Med 18:149-154.

10. Belghiti J, Kayem G, Dupont C, Rudigoz R, Bouvier-Colle M, et al. (2011) Oxytocin during labour and risk of severe postpartum haemorrhage: a 
Citation: Mansy A (2017) Does Labor Augmentation with Oxytocin Increase the Risk of Postpartum Hemorrhage? A Randomized Controlled Trial. Clinics Mother Child Health 14: 268. doi:10.4172/2090-7214.1000268

Page 6 of 6

population-based cohort-nested case-control study. BMJ Open 1 e000514.

11. Khireddine I, Ray CL, Dupont C, Rudigoz RC, Bouvier-Colle MH, et al. (2013) Induction of Labor and Risk of Postpartum Hemorrhage in Low Risk Parturients. PLoS ONE 8: e54858.

12. Bugg GJ, Siddiqui F, Thornton JG (2013) Oxytocin versus no treatment or delayed treatment for slow progress in the first stage of spontaneous labour. Cochrane Database Syst Rev 6: CD007123.

13. Grotegut CA, Paglia MJ, Johnson LN, Thames B, James AH (2011) Oxytocin exposure during labor among women with postpartum hemorrhage secondary to uterine atony. Am J Obstet Gynecol 204: 56.ele6.

14. Combs CA, Murphy EL, Laros RK (1991) Factors associated with postpartum hemorrhage with vaginal birth. Obstet Gynecol 77: 69e76.

15. Waterstone M, Bewley S, Wolfe C (2001) Incidence and predictors of severe obstetric morbidity: case-control study. BMJ 322: 1089e93.

16. Sosa CG, Althabe F, Belizan JM, Buekens P (2010) Use of oxytocin during early stages of labor and its effect on active management of third stage of labor. Am J Obstet Gynecol 204: 238.ele5. 